\title{
Human Chronic Necrotizing Granulomatous Meningoencephalitis: A Novel Case Report
}

\author{
Alexus P. Taddonio ${ }^{a}$ Eric J. Veloso ${ }^{b}$ Kelly J. Baldwin ${ }^{b}$ \\ aTouro College of Osteopathic Medicine, Middletown, NY, USA; b'Geisinger Medical \\ Center, Danville, PA, USA
}

\section{Keywords}

Central nervous system - Meningoencephalitis - Meningitis - Chronic meningitis · Encephalitis - Granulomatous disease - Chronic necrotizing granulomatous meningoencephalitis $\cdot$ New-onset neurological symptoms

\section{Abstract}

Necrotizing and granulomatous meningoencephalitis are common central nervous system diseases known to affect canines. To date, necrotizing granulomatous meningoencephalitis has yet to be described in humans. Current studies of presumed pathogenesis and possible treatment options have only been described in canines. This is a case report of a 55 -year-old female patient who was diagnosed with necrotizing granulomatous meningoencephalitis in the setting of new-onset neurological symptoms without any infectious or malignant source.

(c) 2018 The Author(s)

Published by S. Karger AG, Basel 


\section{Case Reports in Neurology}

\section{Introduction}

Chronic necrotizing and granulomatous meningoencephalitis are idiopathic inflammatory diseases that commonly affect the central nervous system of canines, however, have not been identified in humans yet. These diseases have been associated with specific dog breeds, causing a progressive fatal disease with consistent neuropathological changes [1]. Canine meningoencephalitis is further classified into necrotizing and granulomatous meningoencephalitis based on pathological findings, yet these subclasses are suspected to share a possibly autoimmune pathogenesis [2]. Although these idiopathic inflammatory central nervous system diseases have been identified and investigated within the canine species, necrotizing granulomatous meningoencephalitis has not been readily identified and studied in h umans. Here, we report a case of chronic necrotizing granulomatous meningoencephalitis in an adultfemale patient.

\section{Case Report}

The patient is a 55-year-old right-handed female with a past medical history of previous diagnosis of chronic lymphocytic leukemia, and recurrent TB exposure presenting with newonset daily frontal headaches. She originally presented to her primary care physician with intermittent burning left frontal headaches that were worse with exertion and without associated focal neurologic deficit. Initial neurological examination was unremarkable. MRI of the brain revealed an 11-mm left frontal lobe enhancing lesion with surrounding vasogenic edema, as well as multiple punctate bilateral cortical/subcortical enhancing lesions (Fig. 1). Her headaches began to worsen in intensity and frequency and were associated with new onset right facial tingling and intermittent bilateral upper and lower extremity pain. Extensive infectious, autoimmune, and neoplastic workup was completed and was unremarkable. Malignancy workup included CT of the chest, abdomen, and pelvis, followed by a whole-body bone scan, PET-CT, and flow cytometry which were all negative for malignancy. A summary of the infectious and autoimmune workup can be found in Table 1.

The patient was referred to neurosurgery for open brain biopsy targeting the left frontal enhancing lesion. Postoperative neurologic examination demonstrated a mild expressive aphasia with word finding difficulties. Neuropathology revealed chronic granulomatous inflammation of the brain and meninges. The granulomas noted within the meninges showed central necrosis surrounded by a rim of lymphocytes, plasma cells, and epithelioid histiocytes in addition to eosinophils and giant cells. Marked fibrosis and burnt-out granulomas were seen within both the meninges and brain tissue with dense perivascular lymphoplasmacytic infiltrate along with reactive gliosis within the cerebral cortex. These findings were consistent with chronic necrotizing granulomatous meningoencephalitis. There were no findings on biopsy consistent with mycobacterial infection.

The patient was treated with intravenous 1,000 mg Solumedrol for 3 days followed by a 6 -week prednisone taper. Over the next 6 months, the patient remained clinically stable with mild expressive aphasia. Six months after treatment, she began having staring spells that started with a strange feeling. No EEG correlate wasnoted on long-term EEG monitoring; however, she was started on Lamictal for high suspicion of focal seizures, with complete resolution 


\section{Case Reports in Neurology}

Case Rep Neurol 2018;10:302-308

DOI: $10.1159 / 000494079$

Taddonio et al.: Human Chronic Necrotizing Granulomatous Meningoencephalitis

of symptoms. She remained clinically and radiographically stable without additional treatment for 4 years until the most recent MRI in 2018 suggesting recurrence (Fig. 2).

\section{Discussion}

Chronic necrotizing granulomatous meningoencephalitis, although extensively studied in canines, has yet to be described in humans. Canines can display a wide variety of clinical symptoms depending on the location of the lesions. Common symptoms of necrotizing meningoencephalitis in canines include seizures, paresis, ataxia, visual defects, lethargy, behavioral changes, excessive walking in circles, and death [3,4]. Although necrotizing meningoencephalitis and granulomatous meningoencephalitis can be classified as two distinct processes, the proportion of inflammatory cells does not differ among them, suggesting that they are a spectrum of the same disease with shared pathogenesis [5]. Pathology of these diseases consist of necrosis with infiltration of lymphocytes, plasma cells, and histiocytes within the leptomeninges and the cerebral cortex [5]. Granulomatous lesions with epithelioid cells are seen in addition to perivascular cuffs consisting of lymphocytes, plasma cells, and macrophages [5].

Although the pathogenesis remains unclear, research suggests a possible autoimmune mediated delayed-type hypersensitivity response due to the significant presence of CD3 T-lymphocytes and major histocompatibility complex class II $[5,6]$. It is theorized that the granulomatous nature of the disease further supports an immune mediated etiology. Variants of meningoencephalitis can be associated with specific canine breeds with a higher predilection for females, although both sexes are affected [7].

Studies have yet to identify a single infectious, environmental, or genetics basis, suggesting that multiple factors play a role in disease pathogenesis [6]. Genetic predisposition has been identified in certain breeds [1]. Common infectious causes of canine central nervous system disease, such as canine distemper, Cryptococcus neoformans, Ehrlichia canis, Neospora caninum, Rickettsia rickettsii, and Toxoplasma gondii, have yet to be isolated in canines with necrotizing granulomatous meningoencephalitis [4]. Mycoplasma canis has been isolated at a higher frequency from canines with necrotizing granulomatous meningoencephalitis; however, this difference was not found to be statistically significant when compared to controls [1]. There has yet to be correlation with any viral infections as well, but it remains unclear if possible past exposure could potentiate these diseases [3].

Overall, definitive diagnosis is made postmortem during autopsy of deceased or euthanized canines. It remains difficult to diagnose canines prior to autopsy but living diagnosis can be supported by CSF findings that exclude other infectious etiologies. Additionally, MRI or CT findings consisting of solitary or multiple contrast-enhancing lesions can back up the diagnosis when suspicious for inflammatory meningoencephalitis [7].

There is currently no gold standard treatment for necrotizing granulomatous meningoencephalitis in canines as treatment protocols are largely based on case reports alone and overall it represents a broad spectrum of diseases [6]. The typical treatment for these canines includes immunosuppression with corticosteroids, although neurological symptoms can recur after treatment [7]. Other secondary immunomodulatory drugs such as cyclosporine,cytosine arabinoside, leflunomide, lomustine, and mycophenolate mofetil show promising results but require further evaluation for efficacy [6]. Additionally, use of antiepileptics are suggested in 
canines with seizures [2]. Despite treatment, the prognosis remains poor, yet canines with focal disease tend to survive longer than those with disseminated disease [6].

After a thorough literature review, this is the first case of human chronic necrotizing granulomatous meningoencephalitis to be reported. The similar pathological findings in canines with necrotizing and granulomatous meningoencephalitis suggests that this predominantly canine disease can afflict humans as well. Further research is necessary to determine pathogenesis in both humans and canines. This case demonstrates that the use of glucocorticoids for the treatment of necrotizing granulomatous meningoencephalitis, as in canines, may slow progression of the disease. Our patient remained clinically stable with no evidence of radiologic progression for 4 years after initial steroid treatment. Further research is necessary to determine ideal treatment protocols and to further evaluate the use of immunomodulatory therapy in this disease entity.

\section{Statement of Ethics}

A written consent for publication was obtained from the patient.

\section{Disclosure Statement}

The authors report no conflicts of interest.

\section{Funding Sources}

No targeted funding was reported.

\section{Author Contributions}

Alexus P. Taddonio: responsible for literature review and writing of article. Eric J. Veloso: editing.

\section{References}

1 Barber RM, Porter BF, Li Q, May M, Claiborne MK, Allison AB, et al. Broadly reactive polymerase chain reaction for pathogen detection in canine granulomatous meningoencephalomyelitis and necrotizing meningoencephalitis. J Vet Intern Med. 2012 Jul-Aug;26(4):962-8.

2 Park ES, Uchida K, Nakayama H. Th1-, Th2-, and Th17-related cytokine and chemokine receptor mRNA and protein expression in the brain tissues, $\mathrm{T}$ cells, and macrophages of dogs with necrotizing and granulomatous meningoencephalitis. Vet Pathol. 2013 Nov;50(6):1127-34.

3 Schatzberg SJ, Haley NJ, Barr SC, de Lahunta A, Sharp NJ. Polymerase chain reaction screening for DNA viruses in paraffin-embedded brains from dogs with necrotizing meningoencephalitis, necrotizing leukoencephalitis, and granulomatous meningoencephalitis. J Vet Intern Med. 2005 Jul-Aug;19(4):553-9. 


\section{Case Reports in Neurology}

\begin{tabular}{l|l}
\hline Case Rep Neurol 2018;10:302-308 \\
\hline DOI: 10.1159/000494079 & $\begin{array}{l}\text { (c) 2018 The Author(s). Published by S. Karger AG, Basel } \\
\text { www.karger.com/crn }\end{array}$ \\
\hline
\end{tabular}

Taddonio et al.: Human Chronic Necrotizing Granulomatous Meningoencephalitis

4 Woolcock AD, Wang A, Haley A, Kent M, Creevy KE, Platt SR. Treatment of canine meningoencephalomyel itis of unknown aetiology with mycophenolate mofetil and corticosteroids: 25 cases (2007-2012). Vet Med Sci. 2016 Feb;2(2):125-35.

5 Park ES, Uchida K, Nakayama H.Comprehensive immunohistochemical studies on canine necrotizing meningoencephalitis (NME), necrotizing leukoencephalitis (NLE), and granulomatous meningoencephalomy elitis (GME). Vet Pathol. 2012 Jul;49(4):682-92.

6 Talarico LR, Schatzberg SJ. Idiopathic granulomatous and necrotising inflammatory disorders of the canine central nervous system: a review and future perspectives. J Small Anim Pract. 2010 Mar;51(3):138-49.

7 Coates JR, Barone G, Dewey CW, Vitale CL, Holloway-Azene NM, Sessions JK. Procarbazine as adjunctive therapy for treatment of dogs with presumptive antemortem diagnosis of granulomatous meningoencephalomy elitis: 21 cases (1998-2004). J Vet Intern Med. 2007 Jan-Feb;21(1):100-6.

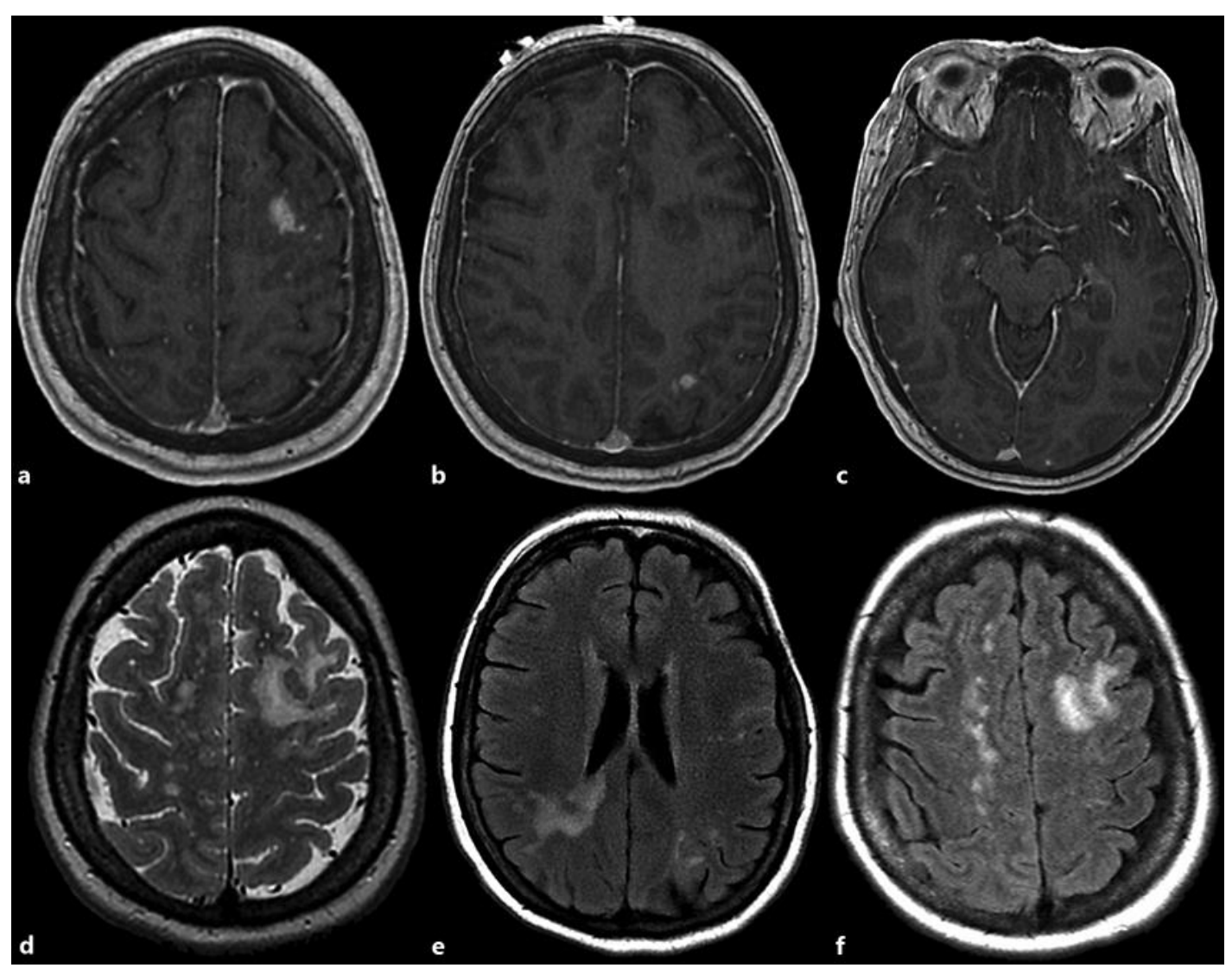

Fig. 1. MRI of the brain with and without gadolinium at presentation. a-c T1 post contrast images demonstrating nodular enhancement in the left frontal cortex (a), left parietal cortex (b), and right occipital cortex (c). d T2 imaging with vasogenic edema in the left frontal cortex with central hypointensity in the area of enhancement. e, f T2 FLAIR with bilateral hyperintensities largely surrounding the area of enhancement. 


\section{Case Reports in Neurology}

Taddonio et al.: Human Chronic Necrotizing Granulomatous Meningoencephalitis

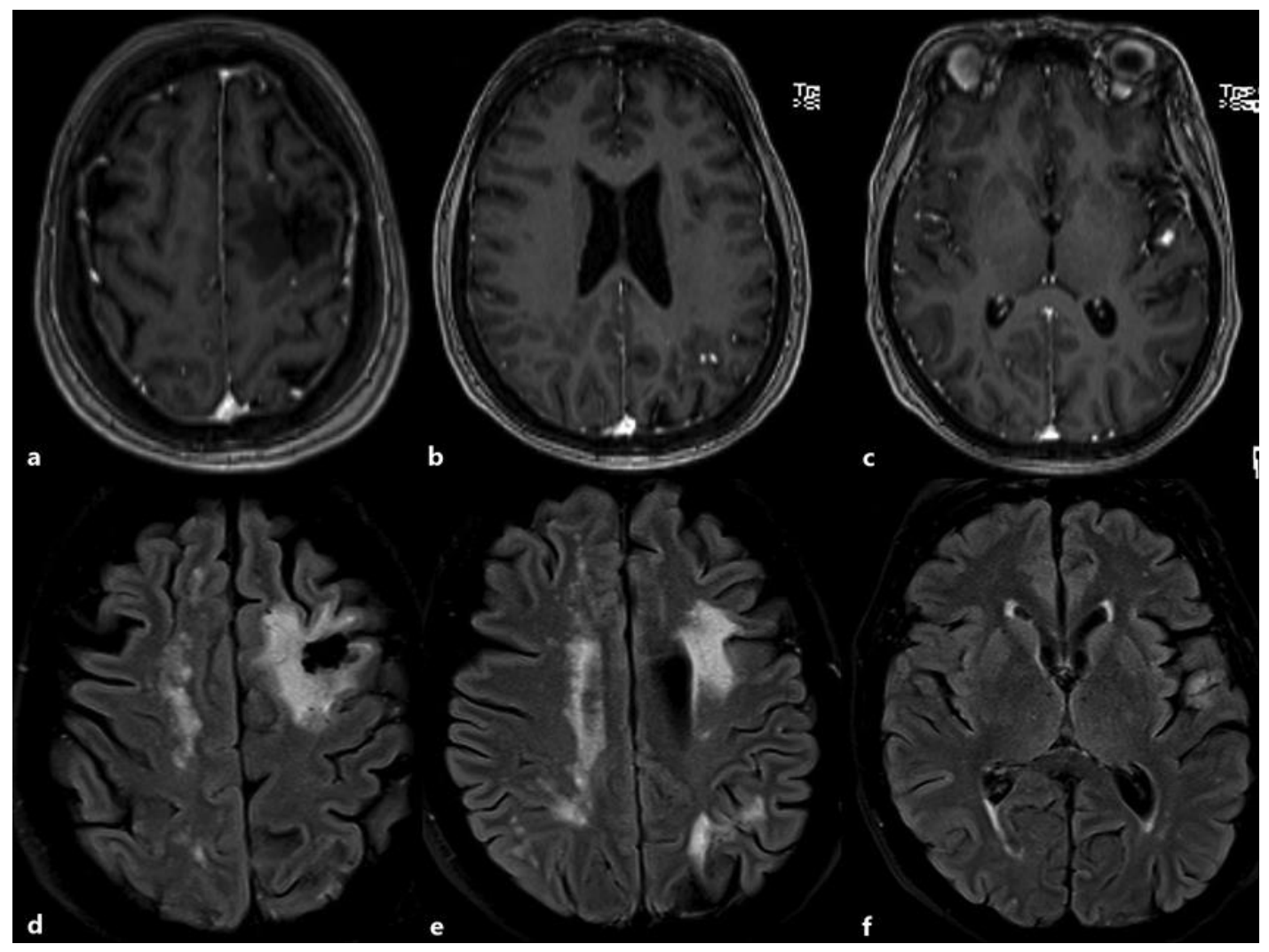

Fig. 2. MRI of the brain with and without gadolinium (4 years later). a-c T1 post contrast images demonstrating new nodular enhancement in the left frontal cortex adjacent to biopsy site (a), two small lesions in the left parietal cortex (b), and new left anterior temporal cortex (c).dT2 imaging with vasogenic edema in the left frontal cortex with central hypointensity in the area of biopsy. e, $f$ T2 FLAIR wit bilateral hyperintensities in the areas of enhancement. 
Table 1. Summary of laboratory and imaging results

\begin{tabular}{|c|c|c|c|c|c|}
\hline \multicolumn{2}{|l|}{ Serum studies } & \multicolumn{2}{|l|}{ CSF studies } & \multicolumn{2}{|l|}{ Imaging/other } \\
\hline $\mathrm{CBC}$ & $\begin{array}{l}\text { WBC }-16.27 \mathrm{k} / \mu \mathrm{L} \\
\mathrm{Hgb}-14.3 \mathrm{~g} / \mathrm{dL} \\
\mathrm{Plt}-411 \mathrm{k} / \mu \mathrm{L}\end{array}$ & Cell count & $\begin{array}{l}\text { RBC - } 15 \\
\text { lymphocyte }-1\end{array}$ & $\begin{array}{l}\text { CT of the chest, } \\
\text { abdomen and } \\
\text { pelvis }\end{array}$ & $\begin{array}{l}\text { mild bullous emphy- } \\
\text { sema, no primary } \\
\text { malignancy or me- } \\
\text { tastases }\end{array}$ \\
\hline $\mathrm{HgbA}_{1 c}$ & $7.8 \%$ & Glucose & $65 \mathrm{mg} / \mathrm{dL}$ & PET-CT & $\begin{array}{l}\text { mild increased } \\
\text { asymmetric uptake } \\
\text { in right tonsil }\end{array}$ \\
\hline ANA & negative & Protein & $44 \mathrm{mg} / \mathrm{dL}$ & $\begin{array}{l}\text { Nuclear medicin } \\
\text { bone scan }\end{array}$ & $\begin{array}{l}\text { e no evidence of skel- } \\
\text { etal metastases }\end{array}$ \\
\hline Complement & $\begin{array}{l}\mathrm{C} 3-161 \mathrm{mg} / \mathrm{dL} \\
\text { (ref. } 90-180 \text { ) } \\
\text { C4 }-36 \mathrm{mg} / \mathrm{dL} \\
\text { (ref. } 10-140 \text { ) }\end{array}$ & Cytology & benign & Mammogram & normal \\
\hline SSA-SSB & negative & $\begin{array}{l}\text { Myelin basic } \\
\text { protein }\end{array}$ & $\begin{array}{l}<2 \mathrm{mg} / \mathrm{L} \\
\text { (ref. } 0-4 \text { ) }\end{array}$ & Colonoscopy & tubular adenoma \\
\hline ANCA & negative & IgG Index & $\begin{array}{l}0.42 \\
\text { (ref.<0.66) }\end{array}$ & PPD & negative \\
\hline ESR & $\begin{array}{l}17 \mathrm{~mm} / \mathrm{h} \\
\text { (ref. } 0-20 \text { ) }\end{array}$ & Oligoclonal bands & $\begin{array}{l}5 \text { gamma-re- } \\
\text { stricted bands } \\
\text { with serum cor- } \\
\text { relate }\end{array}$ & $\mathrm{EEG} \times 4$ & $\begin{array}{l}\text { left frontotemporal } \\
\text { slowing without epi- } \\
\text { leptiform discharges }\end{array}$ \\
\hline CRP & $\begin{array}{l}7.58 \mathrm{ml} / \mathrm{L} \\
\text { (ref. } 0-5 \text { ) }\end{array}$ & $\begin{array}{l}\text { Culture anaerobic/ } \\
\text { obic }\end{array}$ & -no growth & & \\
\hline ACE & $\begin{array}{l}6 \mathrm{U} / \mathrm{L} \\
\text { (ref.9-67) }\end{array}$ & Gram stain & $\begin{array}{l}\text { no organisms or } \\
\text { PMNs }\end{array}$ & & \\
\hline FTA-ABS & nonreactive & Fungal smear & $\begin{array}{l}\text { no yeast or hy- } \\
\text { phae }\end{array}$ & & \\
\hline Quantiferon & negative & Fungal culture & no growth & & \\
\hline $\begin{array}{l}\text { Histoplasmosis/ } \\
\text { blastomycosis IgG }\end{array}$ & negative & $\begin{array}{l}\text { Cryptococcal } \\
\text { antigen }\end{array}$ & negative & & \\
\hline HIV negative & negative & & & & \\
\hline Hepatitis panel & negative & & & & \\
\hline SPEP & normal & & & & \\
\hline
\end{tabular}

